\title{
A PHOTOGRAPHIC METHOD OF MEASURING THE ANGLE OF SQUINT*
}

\author{
BY \\ P. A. GRAHAM AND E. J. NAYLOR \\ Department of Ophthalmology, University of Manchester
}

MeAsurement of the angle of deviation in squint is usually made either objectively or subjectively by means of the major amblyoscope. This instrument has the disadvantage that, although the fixation object is optically at infinity, the known proximity of the apparatus may stimulate convergence (see, for instance, Schapero and Levy, 1953). The readings vary from operator to operator, especially by the objective method, and may differ widely from the visual estimate made by a practised surgeon from observation of the corneal reflex.

An attempt has been made to avoid some of these difficulties by assessing the angle of squint by photographic means. This also provides a permanent record which may be compared with similar records obtained later. The method to be described, though more time-consuming than that using the synoptophore, requires a minimum of co-operation from the patients, in that they are simply required to fix a small light. It places on a quantitative basis the method employed in visual estimation of the angle by the position of the corneal reflex.

\section{Apparatus}

The apparatus consists of a fixed-focus camera employing a large aircraft camera lens of focal length $20^{\prime \prime}$ and relative aperture F 6.3, supported on a rigid steel framework $30^{\prime \prime}$ from the floor. Immediately in front of the film is a $2 \frac{11}{2}$ pneumatic studio shutter, operated by a bulb which can be held in the operator's hand. The shutter mechanism is synchronized with an electronic flash of approximately $1 / 1500$ sec. duration, situated immediately below and in front of the lens. A small fixation light can be moved along a tangent scale in a horizontal plane, at right angles to the principal axis of the system. In the present apparatus the length of this scale is limited by available space to a traverse of $20^{\circ}$ to the right and $25^{\circ}$ to the left. The subject is seated on an adjustable stool, with chin and forehead supported by a suitable rest which is rigidly attached to the camera in order to maintain correct focus. A numbering device is attached to the head-rest for convenience in identifying exposures. The distance between the subject's eyes and the camera lens is $325 \mathrm{~cm}$., this being the distance at which the best focus was found experimentally. Kodak Panatomic-X $35 \mathrm{~mm}$. film, processed with a finegrain developer, gives satisfactory images for measurement.

* Received for publication January 25, 1957 
The processed film is examined by means of a travelling microscope fitted with an eyepiece containing a graticule divided into 100 divisions of $0.05 \mathrm{~mm}$. each. These scale units are used in the calculation of results. The magnification is such that one division of the graticule scale is equivalent to $0.119 \mathrm{~mm}$. at the subject's eye.

\section{Method}

The angle of squint may be assessed by measurement, on a photograph, of the movement of a single point on the eye, or of the relative movement between two individual points. After trial by means of superimposed exposures, the first method was found to be impracticable, principally because of the difficulty of eliminating head movement, particularly in children. The second method eliminates the effect of head movement, and is the method to be described. It will be considered first on the assumption that the eye has a fixed centre of rotation, situated on the optic axis. The effect of this assumption and possible resultant errors will be considered later.

Fig. 1 represents the cornea of an eye with fixation axis along SF and optic axis along SCP. The angle FSC then represents the angle $\gamma$ of physiological optics. The lines LD, MB, which are perpendicular to SF, subtend angles $\omega_{L}$ and $\omega_{M}$ at the centre of curvature of the cornea $C$. The image of the fixation light will lie on the normal to the corneal surface, that is, at a point on the line CX, which may be considered parallel to SF provided the fixation light is sufficiently distant. This image, on a photograph taken from the position of the fixation light, will be displaced from the points $L$ and $\mathrm{M}$ by distances corresponding to $\mathrm{LD}, \mathrm{MB}$ respectively.

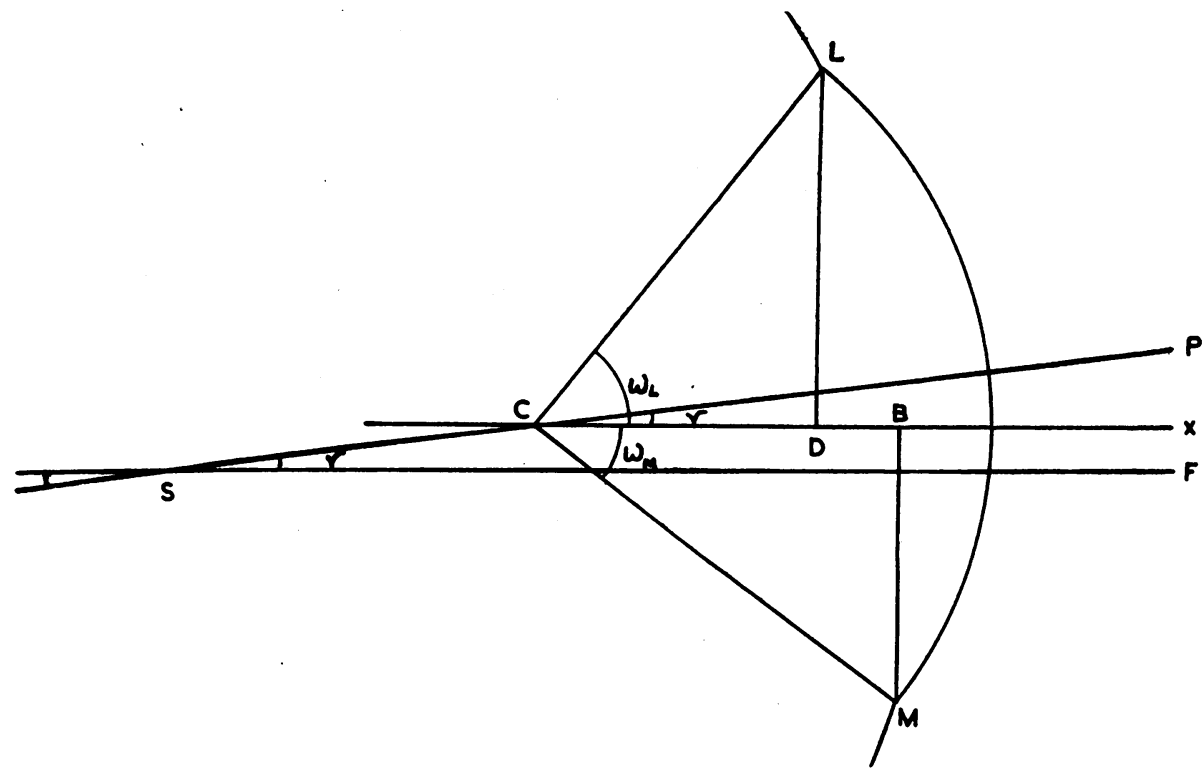

FIG. 1.-Schema of cornea of an eye in the primary position. 
Fig. 2 shows the relationships when the eye has rotated about $S$ through an angle of $\theta^{\circ}$. The fixation axis is now along $\mathrm{SF}^{\prime}$, and the image of the original fixation light will lie on the line $\mathrm{CX}^{\prime}$, which again is parallel to $\mathrm{SF}$ for a distant light source. The displacements of the image from $L$ and $M$ will now be $\mathrm{LD}^{\prime}$ and $\mathrm{MB}^{\prime}$ respectively.

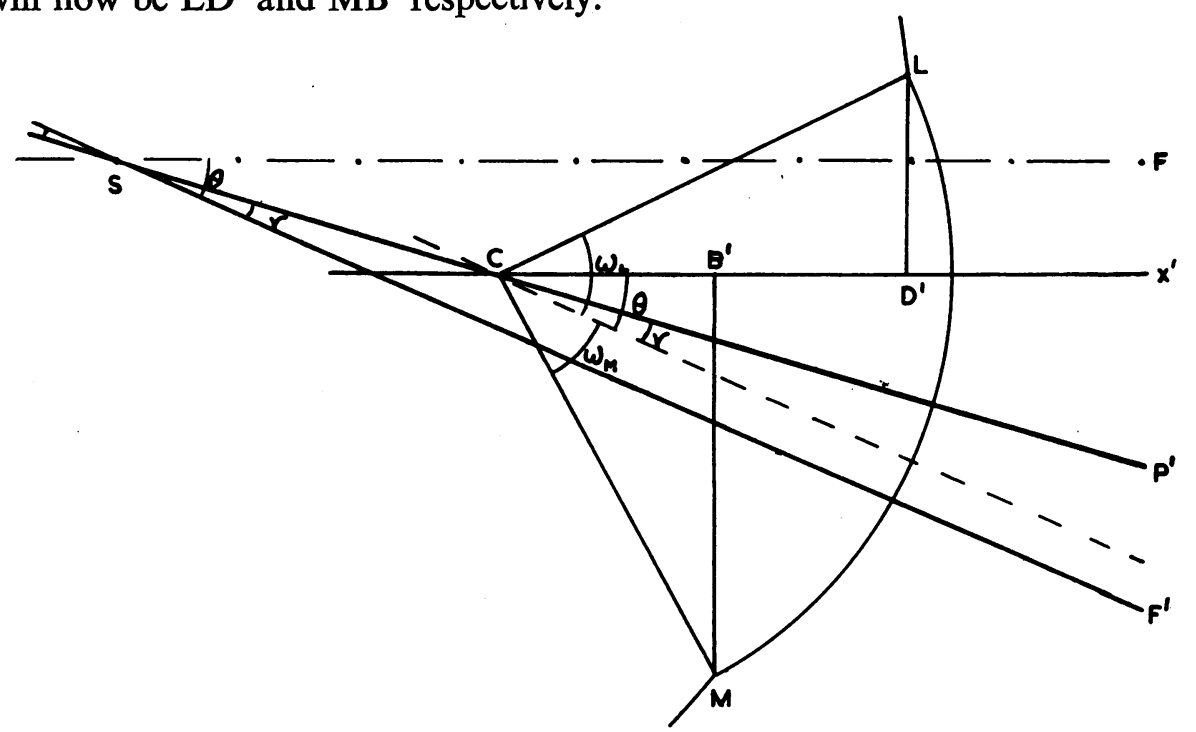

FIG. 2.-Schema of cornea of an eye deviated through an angle of $\theta^{\circ}$.

Let $\mathrm{LD}$ or $\mathrm{MB}=e ; \quad \mathrm{CL}$ or $\mathrm{CM}=q ; \quad \mathrm{LD}^{\prime}$ or $\mathrm{MB}^{\prime}=x$.

The following trigonometrical relationships now hold:

For measurements involving point $\mathrm{L}$,

$$
\begin{aligned}
& \text { and } \quad \begin{array}{ll}
e=q \sin \omega_{L} \\
x=q \sin \left(\omega_{L}-\theta\right)
\end{array} \\
& \text { whence } \quad \tan \omega_{L}=\frac{e \sin \theta}{e \cos \theta-x} \quad \text {. . . . . . } 1(a) \\
& \text { and } \quad \sin \left(\omega_{L}-\theta\right)=\frac{x \sin \omega_{L}}{e} \text {. . . . } 2(a)
\end{aligned}
$$

For measurements involving point $\mathbf{M}$,

$$
\begin{aligned}
& \text { and } \quad x=q \sin \left(\omega_{M}+\theta\right) \\
& \text { whence } \quad \tan \omega_{M}=\frac{e \sin \theta}{x-e \cos \theta} \quad \text {. . . . . . } 1(b) \\
& \text { and } \\
& \sin \left(\omega_{M}+\theta\right)=\frac{x \sin \omega_{M}}{e} \text {. . . . . } 2(b)
\end{aligned}
$$

The value of $\omega$ can be determined from Equation 1 by measuring $e$ and $x$ at a known value of $\theta$, and it may be used in Equation $2(a)$ or $2(b)$ with a new 
value of $x$ to determine an unknown value of $\theta$. The method is independent of the value of angle $\gamma$. It will be noted, however, that the values of $\omega_{L}$ and $\omega_{M}$ will differ owing to the angle $\gamma$ and the asymmetry of the cornea. Care must be taken, therefore, always to use the value of $\omega$ relevant to the reference point in use, and to pay due attention to the direction of movement of the fixation axis relative to this point. In practice, the reference point chosen is one of the limbal margins, and in cases where the fixation point is moved to the opposite side from the limbus chosen Equation $2(a)$ is used, whereas in cases where the fixation point is moved towards this limbus, Equation $2(b)$ is used.

\section{Procedure}

With the normally-fixing eye occluded, three exposures are made with the squinting eye fixing centrally. The fixation light is then moved to the angle chosen for the determination of $\omega$ (as explained below the angle chosen should not be less than $15^{\circ}$ ) and three further exposures are made with the non-squinting eye still occluded and the squinting eye fixing the light. The fixation light is returned to its central position, the occluder is removed, the normally-fixing eye is allowed to take up fixation, and a third series of three photographs is taken.

The mean distance of the corneal reflex from the temporal limbus is determined from readings taken independently by two observers, and a value of $\omega$ is obtained from Equation 1, using the angular displacement of the fixation light as the value of $\theta$, and the mean of three readings from the first two sets of exposures as values of $e$ and $x$ respectively. This value of $\omega$ is then substituted in Equation $2(a)$ or $2(b)$ together with the value of $\theta$ as above and the new value of $x$; in this case, $x$ is the mean of the three readings comprising the third set of exposures.

\section{Results}

For Known Fixation Angle.--In order to assess the variations in $\omega$ from eye to eye, and with the fixation angle, measurements were made on four normal subjects and on three children with convergent squint. In the normal subjects, $x$ was measured for four values of $\theta\left(5^{\circ}, 10^{\circ}, 15^{\circ}\right.$ and $\left.20^{\circ}\right)$ both to right and left and for both eyes. The resultant values of $\omega$ are shown in Table I (opposite). These values show a larger variation between $5^{\circ}$ and $10^{\circ}$ than between $15^{\circ}$ and $20^{\circ}$.

In the three children, $\omega$ was determined for at least one angle other than the expected angle of squint. The results in Table II (opposite) show the variation in the value of $\omega$ and its effect on the value of the angle of squint.

Cases of Squint.-Fifteen children with convergent strabismus were examined on the occasion of admission to hospital for operation. Their ages ranged from 7-15 years, and the angles of squint without correction 
TABLE I

VALUES OF $\omega$ OBTAINED FOR DIFFERENT ANGLES OF FIXATION IN NORMAL SUBJECTS

\begin{tabular}{|c|c|c|c|c|c|c|}
\hline \multirow{3}{*}{$\begin{array}{c}\text { Subject } \\
\text { No. }\end{array}$} & \multirow{3}{*}{ Eye } & \multicolumn{5}{|c|}{ Fixation Point } \\
\hline & & \multirow{2}{*}{ Direction } & \multicolumn{4}{|c|}{ Displacement } \\
\hline & & & $5^{\circ}$ & $10^{\circ}$ & $15^{\circ}$ & $20^{\circ}$ \\
\hline \multirow{4}{*}{1} & $\mathbf{R}$ & \multirow{2}{*}{ Right } & $52^{\circ} 08^{\prime}$ & $46^{\circ} 07^{\prime}$ & $45^{\circ} 28^{\prime}$ & $45^{\circ} 00^{\prime}$ \\
\hline & $\mathbf{L}$ & & $50^{\circ} 12^{\prime}$ & $53^{\circ} 23^{\prime}$ & $53^{\circ} 33^{\prime}$ & $52^{\circ} 04^{\prime}$ \\
\hline & $\mathbf{R}$ & \multirow{2}{*}{ Left } & $52^{\circ} 05^{\prime}$ & $52^{\circ} 16^{\prime}$ & $54^{\circ} 37^{\prime}$ & $52^{\circ} 05^{\prime}$ \\
\hline & $\mathbf{L}$ & & $53^{\circ} 33^{\prime}$ & $46^{\circ} 43^{\prime}$ & $43^{\circ} 28^{\prime}$ & $46^{\circ} 53^{\prime}$ \\
\hline \multirow{4}{*}{2} & $\mathbf{R}$ & \multirow{2}{*}{ Right } & $43^{\circ} 16^{\prime}$ & $44^{\circ} 59^{\prime}$ & $43^{\circ} 40^{\prime}$ & $43^{\circ} 51^{\prime}$ \\
\hline & $\mathbf{L}$ & & $54^{\circ} 52^{\prime}$ & $52^{\circ} 33^{\prime}$ & $53^{\circ} 46^{\prime}$ & $51^{\circ} 46^{\prime}$ \\
\hline & $\mathbf{R}$ & \multirow{2}{*}{ Left } & $51^{\circ} 19^{\prime}$ & $50^{\circ} 09^{\prime}$ & $53^{\circ} 41^{\prime}$ & $51^{\circ} 05^{\prime}$ \\
\hline & L & & $46^{\circ} 28^{\prime}$ & $42^{\circ} 13^{\prime}$ & $42^{\circ} 00^{\prime}$ & $41^{\circ} 35^{\prime}$ \\
\hline \multirow{4}{*}{3} & $\mathbf{R}$ & \multirow{2}{*}{ Right } & $45^{\circ} 42^{\prime}$ & $45^{\circ} 03^{\prime}$ & $38^{\circ} 15^{\prime}$ & $38^{\circ} 18^{\prime}$ \\
\hline & $\mathbf{L}$ & & $55^{\circ} 27^{\prime}$ & $56^{\circ} 11^{\prime}$ & $52^{\circ} 34^{\prime}$ & $53^{\circ} 36^{\prime}$ \\
\hline & $\mathbf{R}$ & \multirow{2}{*}{ Left } & $50^{\circ} 32^{\prime}$ & $60^{\circ} 28^{\prime}$ & $55^{\circ} 28^{\prime}$ & $53^{\circ} 18^{\prime}$ \\
\hline & L & & $44^{\circ} 33^{\prime}$ & $46^{\circ} 00^{\prime}$ & $38^{\circ} 50^{\prime}$ & $38^{\circ} 54^{\prime}$ \\
\hline \multirow{4}{*}{4} & $\mathbf{R}$ & \multirow{2}{*}{ Right } & $40^{\circ} 06^{\prime}$ & $46^{\circ} 52^{\prime}$ & $41^{\circ} 20^{\prime}$ & $40^{\circ} 12^{\prime}$ \\
\hline & L & & $48^{\circ} 24^{\prime}$. & $58^{\circ} 43^{\prime}$ & $53^{\circ} 42^{\prime}$ & $56^{\circ} 05^{\prime}$ \\
\hline & $\mathbf{R}$ & \multirow{2}{*}{ Left } & $63^{\circ} 42^{\prime}$ & $56^{\circ} 44^{\prime}$ & $52^{\circ} 05^{\prime}$ & $53^{\circ} 30^{\prime}$ \\
\hline & $\mathbf{L}$ & & $47^{\circ} 36^{\prime}$ & $44^{\circ} 04^{\prime}$ & $40^{\circ} 10^{\prime}$ & $40^{\circ} 36^{\prime}$ \\
\hline
\end{tabular}

TABLE II

VALUES OF $\omega$ OBTAINED FOR DIFFERENT ANGLES OF FIXATION SHOWING EFFECT ON ESTIMATED ANGLE OF SQUINT

\begin{tabular}{c|l|c|c|c}
\hline \multicolumn{2}{c|}{ Subject No. } & $\begin{array}{c}\text { Fixation Angle } \\
\text { used to } \\
\text { Determine } \omega\end{array}$ & $\omega$ & $\begin{array}{c}\text { Calculated Value } \\
\text { for Angle of } \\
\text { Squint }\end{array}$ \\
\hline 1 & With Glasses & $5^{\circ}$ & $60^{\circ} 53^{\prime}$ & $66^{\circ} 05^{\prime}$ \\
\cline { 2 - 5 } & Without Glasses & $15^{\circ}$ & $55^{\circ} 45^{\prime}$ & $5^{\circ} 07^{\prime}$ \\
\hline 2 & No Glasses & $5^{\circ}$ & $60^{\circ} 21^{\prime}$ & $18^{\circ} 45^{\prime}$ \\
& & $20^{\circ}$ & $60^{\circ} 09^{\prime}$ & $18^{\circ} 39^{\prime}$ \\
\hline 3 & & $15^{\circ}$ & $62^{\circ} 02^{\prime}$ & $33^{\circ} 10^{\prime}$ \\
& & $5^{\circ}$ & $64^{\circ} 07^{\prime}$ & $31^{\circ} 56^{\prime}$ \\
& With Glasses & $15^{\circ}$ & $69^{\circ} 18^{\prime}$ & $38^{\circ} 33^{\prime}$ \\
\hline
\end{tabular}


of the refractive error ranged from $5^{\circ}-45^{\circ}$. All the patients were being operated on for cosmetic reasons and none had binocular vision. The angle of squint was measured objectively on the synoptophore by the orthoptic department staff immediately before photography. If the patient wore glasses both synoptophore and photographic measurements were made with and without the child's own spectacles. It was found that the large diffuse reflections from the lenses did not interfere with the photographic method, as they were easily distinguished from the small, sharp corneal reflex. The results of this series are shown in Table III (opposite).

\section{Discussion}

Possible sources of error fall into two groups:

(1) Those due to theoretical assumptions regarding the optical constants of the eye;

(2) Those due to inaccuracies of measurement in practice.

The former may be listed as follows:

$1(a)$. - The centre of rotation may not be a fixed point in relation to the eye and may not lie on the optic axis.

Numerous attempts have been made to establish the position of a point about which the eye can be considered to rotate (see, for instance, DukeElder, 1938). According to Park and Park (1933) the maximum translatory movement of the centre of rotation in' space amounts to about $1 \mathrm{~mm}$.; Emsley (1946) considers that the centre of rotation may be taken as approximately a fixed point about $15 \mathrm{~mm}$. back from the anterior surface of the cornea and displaced about $1.67 \mathrm{~mm}$. to the nasal side of the primary line (fixation axis in the primary position of the eye). Whatever approximation is adopted, its position within the eye will vary between individuals and with the direction of fixation, but is sufficiently small to have no serious effect on the value of $\omega$ or $\theta$. Any movement with reference to co-ordinates in space will apply to all parts of the eye and affects the angle of view of the cornea. At the distance employed in our apparatus this effect is negligible.

$1(b)$.- The source and the camera are situated at a finite distance from the eye, and incident rays are not parallel. At the distance of $325 \mathrm{~cm}$. used, the departure from parallelism is negligible.

$1(c)$.- The value of the angle of squint obtained will be increased by approximately the amount of convergence at the operating distance. This is no disadvantage, provided it is not taken as a true measurement for fixation at infinity. The difference in any case is only about $0 \cdot 5^{\circ}$.

$1(d)$.-The cornea is not truly spherical, as the corneal radius of curvature increases steadily towards the periphery, and the value of $\omega$ depends on the 
TABLE III

ESTIMATED ANGLES OF DEVIATION IN FIFTEEN CASES OF CONVERGENT SQUINT

\begin{tabular}{|c|c|c|c|c|c|}
\hline No & $\begin{array}{l}\text { Refraction } \\
\text { (if worn) }\end{array}$ & Diagnosis & Glasses & $\begin{array}{l}\text { Angle on } \\
\text { Synopto- } \\
\text { phore }\end{array}$ & $\begin{array}{l}\text { Photographic } \\
\text { Measurement }\end{array}$ \\
\hline 1 & - & $\begin{array}{l}\text { Right amblyopia } \\
\text { Right concomitant } \\
\text { convergent squint }\end{array}$ & & $10^{\circ}$ & $18^{\circ}$ \\
\hline \multirow[t]{2}{*}{2} & \multirow{2}{*}{$\begin{array}{l}\mathrm{R}+4 \cdot 5 \mathrm{D} \text { sph. } \\
\mathrm{L}+4: 0 \mathrm{D} \text { sph. }\end{array}$} & \multirow[t]{2}{*}{ Alternating squint } & with & $8^{\circ}$ & $13^{\circ}$ \\
\hline & & & without & $20^{\circ}$ & $22^{\circ}$ \\
\hline \multirow[t]{2}{*}{3} & \multirow{2}{*}{$\begin{array}{l}\mathrm{R}+6.00 \mathrm{D} \text { sph. } \\
\mathrm{L}+5 \cdot 50 \mathrm{D} \text { sph. }\end{array}$} & \multirow{2}{*}{$\begin{array}{l}\text { Right concomitant } \\
\text { convergent squint } \\
\text { Right amblyopia }\end{array}$} & with & $10^{\circ}$ & $15^{\circ}$ \\
\hline & & & without & $20^{\circ}$ & $27^{\circ}$ \\
\hline \multirow[t]{2}{*}{4} & \multirow{2}{*}{$\begin{array}{l}\mathrm{R}+8 \cdot 0 /+1.0 \times 90 \\
\mathrm{~L}+6 \cdot 5 /+0.75 \times 90\end{array}$} & \multirow{2}{*}{$\begin{array}{l}\text { Right concomitant } \\
\text { convergent squint } \\
\text { Right amblyopia }\end{array}$} & with & $15^{\circ}$ & $17^{\circ}$ \\
\hline & & & without & $35^{\circ}$ & $29^{\circ}$ \\
\hline \multirow[t]{2}{*}{5} & \multirow{2}{*}{$\begin{array}{l}\mathrm{R}+2 \cdot 0 \mathrm{D} \text { sph. } \\
\mathrm{L}+2 \cdot 0 \mathrm{D} \mathrm{sph} .\end{array}$} & \multirow[t]{2}{*}{$\begin{array}{l}\text { Left concomitant } \\
\text { convergent squint }\end{array}$} & with & $5^{\circ}$ & $6^{\circ}$ \\
\hline & & & without & $18^{\circ}$ & $19^{\circ}$ \\
\hline 6 & - & $\begin{array}{l}\text { Right concomitant } \\
\text { convergent squint } \\
\text { Right amblyopia }\end{array}$ & & $25^{\circ}$ & $33^{\circ}$ \\
\hline 7 & - & $\begin{array}{l}\text { Left concomitant } \\
\text { convergent squint } \\
\text { Left amblyopia }\end{array}$ & & $40-45^{\circ}$ & $38^{\circ}$ \\
\hline 8 & - & $\begin{array}{l}\text { Right concomitant } \\
\text { convergent squint }\end{array}$ & & $8^{\circ}$ & $13^{\circ}$ \\
\hline \multirow[t]{2}{*}{9} & \multirow{2}{*}{$\begin{array}{l}\mathbf{R}+3.75 \mathrm{D} \mathrm{sph} . \\
\mathrm{L}+2.75 \mathrm{D} \text { sph. }\end{array}$} & \multirow{2}{*}{$\begin{array}{l}\text { Left concomitant } \\
\text { convergent squint } \\
\text { Left amblyopia }\end{array}$} & with & $15^{\circ}$ & $16^{\circ}$ \\
\hline & & & without & $25^{\circ}$ & $29^{\circ}$ varying to $11^{\circ *}$ \\
\hline \multirow[t]{2}{*}{10} & \multirow{2}{*}{$\begin{array}{l}\mathbf{R}+6 \cdot 25 /+0.5 \times 90 \\
\mathrm{~L}+5 \cdot 5 \mathrm{D} \text { sph. }\end{array}$} & \multirow{2}{*}{$\begin{array}{l}\text { Left concomitant } \\
\text { convergent squint } \\
\text { Left amblyopia }\end{array}$} & with & $8^{\circ}$ & $17^{\circ}$ \\
\hline & & & without & $30^{\circ}$ & $38^{\circ}$ \\
\hline 11 & & $\begin{array}{l}\text { Left concomitant } \\
\text { convergent squint } \\
\text { Left amblyopia }\end{array}$ & & $30^{\circ}$ & $36^{\circ}$ \\
\hline \multirow[t]{2}{*}{12} & \multirow{2}{*}{$\begin{array}{l}\mathrm{R}+2 \cdot 0 /+1 \cdot 5 \times 90 \\
\mathrm{~L}+2 \cdot 0 /+1 \cdot 5 \times 90\end{array}$} & \multirow[t]{2}{*}{$\begin{array}{l}\text { Left concomitant } \\
\text { convergent squint }\end{array}$} & with & $5^{\circ}$ & $6^{\circ}$ \\
\hline & & & without & $18^{\circ}$ & $12^{\circ}$ \\
\hline 13 & - & $\begin{array}{l}\text { Right concomitant } \\
\text { convergent squint } \\
\text { Right amblyopia }\end{array}$ & & $25^{\circ}$ & $25^{\circ}$ \\
\hline 14 & - & $\begin{array}{l}\text { Right concomitant } \\
\text { convergent squint } \\
\text { Right amblyopia }\end{array}$ & & $40-45^{\circ}$ & $47^{\circ}$ \\
\hline 15 & - & $\begin{array}{l}\text { Right concomitant } \\
\text { convergent squint }\end{array}$ & & $10^{\circ}$ & $4^{\circ}$ \\
\hline
\end{tabular}

* Noted to be variable before photographing 
position of the centre of curvature for the zone in use. Unless, therefore, the reflex is formed by the almost spherical optical zone of the cornea, the value of $\omega$ will change as more peripheral parts of the cornea are used. This means that, unless the same zone is used for the determination of $\omega$ and $\theta$, a false estimate of the angle of deviation will be obtained. The error is minimized by determining $\omega$ at an angle as near as possible to the expected angle of squint. As the optical zone is used for deviations of up to $15^{\circ}$, it is unnecessary, and as discussed below, undesirable, to use angles of less than $15^{\circ}$ for determining $\omega$, but, as the eye deviates beyond $15^{\circ}$ and flatter peripheral zones form the image, an alteration in the value of $\omega$ may be expected, and it is then advisable to determine $\omega$ for an angle near to the expected angle of squint, which may be assessed visually before photographing.

2 (a) Variations in $\omega$.-As noted above, values of $\omega$ show a larger variation between $5^{\circ}$ and $10^{\circ}$ than between $15^{\circ}$ and $20^{\circ}$. This is due principally to errors in scale reading, which have a much greater effect where $\theta$ is small and the quantity $e \cos \theta-x$ is also small. In order to minimize such errors, it is advisable not to use angles of less than $15^{\circ}$ for the determination of $\omega$. At $5^{\circ}$, the error due to a misreading of the scale by one division alters the value of $\omega$ by about $8^{\circ}$, whereas at $10^{\circ}, 15^{\circ}$, and $20^{\circ}$ the corresponding figures are $4^{\circ}, 2 \cdot 5^{\circ}$, and $1.5^{\circ}$ respectively. As would be expected, values of $\omega$ vary from subject to subject, and also to a much lesser extent between the right and left eyes of the same subject.

2 (b) Variations between Synoptophore and Camera Measurements.Table III shows that there are considerable differences between the angles estimated objectively by the synoptophore and by the photographic method. This is in accord with the experience of some surgeons who have noted that on occasion the visual estimate obviously fails to agree with the synoptophore reading. It is not proposed to discuss these fully here, as it is intended to investigate a larger series of patients to confirm and elucidate these discrepancies. They are in part due to the experimental error in both synoptophore and camera measurements. In the photographic method the six readings which are averaged to obtain each value vary by an average of less than one scale division. A cumulative error of one scale division in each of the three values used in calculating a $20^{\circ}$ squint will result in an error of $2 \cdot 5^{\circ}$.

Fixation can be controlled to some extent by placing the operator near the patient so that the exposure is not made during a period when fixation is lost or unsteady. Difficulties in measurement arise chiefly in the identification of a clear reference point at the limbus, as this may extend over two to three scale divisions without any abrupt line of demarcation. As, however, all measurements are made in succession, it is possible with practice to measure from a corresponding point in this zone in each photograph of a 
given patient. This is the cause of some of the variations in readings by two observers on the same photograph, and it is worth noting that in these cases every measurement on that subject tends to be assessed as larger by one observer. This to some extent nullifies the difference in individual readings.

\section{Summary}

A method of estimating the angular deviation of the eyes of subjects with lateral squints by measurement on photographs is described. Theoretical and practical sources of error are discussed.

We wish to express our gratitude to Mr. O. M. Duthie and Dr. A. Stanworth for allowing us to see their patients.

\section{REFERENCES}

DUKe-EldER, W. S. (1938). “Text-book of Ophthalmology”, vol. 1, p. 591. Kimpton, London. EmSLeY, H. H. (1946). " "Visual Optics", 4th ed., p. 536. Hatton Press, London.

PARK, R. S., and PARK, G. E. (1933). Amer. J. Physiol., 104, 545.

SCHAPERO, M., and LeVY, M. (1953). Amer. J. Optom., 30, 403. 